\title{
Regulation of Retinol Binding Protein 4 Expression and its Relation to Adipogenesis in Bovine Adipocytes
}

\author{
${ }^{1}$ Abd Eldaim Mabrouk Attia and ${ }^{2}$ Mabrouk Ragab EL-Sabagh \\ ${ }^{1}$ Department of Biochemistry and Chemistry of Nutrition, \\ Faculty of Veterinary Medicine, Menoufiya University, El Sadat City, Egypt \\ ${ }^{2}$ Department of Nutrition and Clinical Nutrition, \\ Faculty of Veterinary Medicine, Kafrelsheikh University, Kafr El-Sheikh 33516, Egypt
}

Received 2012-07-16, Revised 2012-07-25; Accepted 2012-08-15

\begin{abstract}
Adipogenesis is of great importance in beef cattle. Recent findings indicate that glucose, a substrate for fatty acid biosynthesis and retinoic acid enhance adipogenesis in bovine intramuscular adipocytes. However, other recent findings indicate that Retinol-Binding Protein 4 (RBP4) interferes with glucose uptake and utilization by rodents' adipocytes. In this study we examined the regulation of RBP4 expression and its relation to adipogenesis in bovine adipocytes. Stromal vascular cells were prepared by collagenase digestion from subcutaneous and intramuscular adipose tissues of Japanese black steers. RT-PCR revealed that RBP4 mRNA was expressed in bovine adipose tissue. Northern and Western Blot analysis showed that RBP4 was highly expressed and secreted from bovine preadipocytes. However, RBP4 expression and secretion were significantly reduced by induction of the adipogenic differentiation of preadipocytes into mature adipocytes. Glucose and retinoic acid have a suppressive effect on RBP4 expression and secretion from intramuscular adipocytes. Retinoic acid significantly decreased RBP4 expression in Japanese black steer subcutaneous adipocytes. Retinoic acid itself had no effect on lipid accumulation in subcutaneous adipocytes however, retinoic acid enhanced lipid accumulation in these adipocytes after addition of acetate, a substrate for fatty acid biosynthesis in subcutaneous adipocytes. This study indicated a negative correlation between adipogenesis and RBP4 expression in bovine adipocytes and suggests possible inhibitory effect of RBP4 on adipogenesis.
\end{abstract}

Keywords: Bovine Intramuscular Adipocytes, Adipogenesis, Retinol-Binding Protein 4 (RBP4)

\section{INTRODUCTION}

Retinol Binding Protein (RBP), known as Retinol Binding Protein 4 (RBP4), is a single polypeptide chain $21-\mathrm{kDa}$ protein. RBP4 is responsible for mobilization and transportation of retinol from its storage sites (liver and adipose tissue) to peripheral tissues, which express a specific membrane receptor for RBP4 (STRA6) that mediates retinol uptake from RBP4retinol complex (Kawaguchi et al., 2007 and Berry et al., 2012). Thus, disruption of RBP4 expression reduces circulating RBP4 and retinol levels and subsequently reduces retinol bioavailability and functions (Dixon and Goodman 1987; Marinari et al., 1987; Yang et al., 2005; Manolescu et al., 2010).

Initially RBP4 was thought to be liver specific protein. However, recent findings indicate that cells of extra hepatic tissues including adipose tissue have the capability to synthesize RBP4, but at lower levels than liver (Blomhoff and Blomhoff, 2006). In addition, human and rodents adipocytes can synthesize and secrete RBP4 in a differentiation dependent manner (Manolescu et al., 2010; Janke et al., 2006).

\footnotetext{
Corresponding Author: Abd Eldaim Mabrouk Attia, Department of Biochemistry and Chemistry of Nutrition, Faculty of Veterinary Medicine, Menoufiya University, El Sadat City, Egypt
} 
Retinol (vitamin A) plays important roles in many physiological functions including cell differentiation through its active form, Retinoic Acid (RA). RA via its nuclear receptors, Retinoic Acid Receptors (RARs) and Retinoid X Receptors (RXRs) modulates the transcription of its target genes including adipogenic genes (Shulman and Mangelsdorf, 2005). Effects of retinol on adipogenesis in animals are differed according to the animal species and the adipose tissue depots (Kawada et al., 1990; Safonova et al., 1994; Ohyama et al., 1998; Arnett et al., 2007; Redonnet et al., 2008).

Adipogenesis in intramuscular adipose tissue of beef cattle is of great importance because it affects meat quality in the form of marbling scores, which has great economical importance. Glucose has an important role in adipogenesis in bovine intramuscular adipocytes as a substrate for fatty acid biosynthesis (Smith et al., 2009). RBP4 especially that produced from adipose tissue interferes with glucose uptake and utilization in adipocytes of rodents and human (Yang et al., 2005; Ost et al., 2007). In contrast, RA enhances glucose uptake by tissues through reducing RBP4 production, especially that from adipose tissue (Mercader et al., 2008; Manolescu et al., 2010).

Thus, increasing glucose uptake and utilization in intramuscular adipocytes of beef cattle by decreasing RBP4 production and/or increasing blood glucose level, may increase adipogenesis in intramuscular adipose tissue and subsequently improve marbling scores and meat quality.

Although RBP4, retinol and glucose play important roles in adipocytes metabolism, there is no report concerning the regulation of RBP4 expression and its relation to adipogenesis in bovine intramuscular adipocytes.

In this study we investigated the correlation between RBP4 expression and adipogenesis in bovine intramuscular adipocytes as well as we examined the regulation of RBP4 expression by RA in bovine adipocytes cultured in the presence of different glucose concentrations.

\section{MATERIALS AND METHODS}

\subsection{Materials}

Dulbecco's Modified Eagles' Medium (DMEM) with normal $(5.5 \mathrm{mM})$ glucose, all-trans Retinoic Acid (RA), Collagenase and dexamethasone were purchased from Wako Pure Chemicals Co. (Osaka, Japan). DMEM/F12 medium containing $17.5 \mathrm{mM}$ glucose, Hank's balanced salt solution; bovine insulin and Isobutyl Methyl Xanthine (IBMX) were bought from Sigma-Aldrich Fine Chemical (St. Louis, MO, USA). Fetal Calf Serum (FCS) was from Trace Scientific Ltd. (Melbourne, Australia).
Purified RBP4 and RBP4 antibody were given as a gift from Prof. Toru Miyamoto (National Institute of Animal Health, Japan).

\subsection{Isolation of Stromal Vascular Cells from Bovine Intramuscular Adiposetissue and Their Culture}

Subcutaneous adipose tissues obtained from 3 Holstein cows and Subcutaneous and Intramuscular adipose tissues obtained from 3 Japanese black steers were dissected into small pieces in Hank's balanced salt solution containing $2 \mathrm{mg} \mathrm{mL}^{-1}$ collagenase and $0.1 \%$ BSA in sterile $50 \mathrm{~mL}$ plastic tubes. Following digestion at $37^{\circ} \mathrm{C}$ for $90 \mathrm{~min}$ with gentle shaking, the solution was filtered through sterile nylon mesh with $80 \mu \mathrm{m}$ pores. The filtrate was centrifuged at $1,000 \times g$ for $5 \mathrm{~min}$ at room temperature. The collected cells mainly consisting of stromal vascular cells were treated with an erythrocyte lysis buffer $(154 \mathrm{mM} \mathrm{NH} 4 \mathrm{Cl}, 10 \mathrm{mM} \mathrm{KHCO} 3$ and 1 mM EDTA) for $5 \mathrm{~min}$ and washed twice with DMEM containing $10 \% \mathrm{FCS}, 100 \mathrm{U} \mathrm{mL}^{-1}$ penicillin and $100 \mu \mathrm{g}$ $\mathrm{mL}^{-1}$ streptomycin. Cells were cultured in DMEM $(5.5$ $\mathrm{mM}$ glucose) containing $10 \%$ FCS on collagen-coated dishes (Iwaki-Asahi techno Glass, Chiba, Japan) and media were changed every 2 days. The cells between third and fifth passages were used for the experiments.

When bovine stromal vascular cells reached to confluence (referred to day 0). Cells were further cultured in DMEM/F12 (17.5 mM glucose) containing $1.5 \%$ FCS, $0.5 \mathrm{mM}$ IBMX, $1 \mu \mathrm{M}$ dexamethasone, sodium acetate $(10 \mathrm{mM})$, troglitazone $10 \mu \mathrm{M}$ and $10 \mu \mathrm{g}$ $\mathrm{mL}^{-1}$ insulin for 2 days. Subsequently cells were cultured in the medium containing $1.5 \%$ FCS, sodium acetate $(10$ $\mathrm{mM})$, troglitazone $10 \mu \mathrm{M}$ and $10 \mu \mathrm{g} \mathrm{mL} \mathrm{m}^{-1}$ insulin replaced every 2 days until day 12 to achieve cell differentiation to mature adipocytes.

To investigate the regulation of RBP4 expression and secretion in intramuscular adipocytes with RA, Stromal vascular cells isolated from Japanese black steers intramuscular adipose tissue were cultured in DMEM with normal glucose $(5.5 \mathrm{mM})$ or DMEM/F12 with high glucose $(17.5 \mathrm{mM})$ containing $1.5 \% \mathrm{FCS}, 0.5 \mathrm{mM}$ IBMX, $1 \mu \mathrm{M}$ dexamethasone and $10 \mu \mathrm{g} \mathrm{mL}^{-1}$ insulin for 2 days. Subsequently they were cultured in medium containing $1.5 \% \mathrm{FCS}$ and $10 \mu \mathrm{g} \mathrm{mL}^{-1}$ insulin replaced every 2 days until day 12 . Where indicated retinoic acid (RA $1 \mu \mathrm{M})$ or DMSO as a solvent control were added to the medium from day 0 .

To investigate the regulation of RBP4 expression in subcutaneous adipocytes with RA Stromal vascular cells, isolated from subcutaneous adipose tissues of Japanese black steers and Holstein cows were cultured in high glucose medium and treated as in case of intramuscular adipocytes. 


\subsection{Oil red O Staining and Lipid Quantification}

Cultured bovine stromal vascular cells after 12 days from the induction of adipogenic differentiation were fixed with $10 \%$ formalin in isotonic phosphate buffer for $1 \mathrm{~h}$, stained with $0.5 \%$ oil red $\mathrm{O}$ in $60 \%$ isopropyl alcohol for $1 \mathrm{~h}$ and rinsed extensively with water. After visualization and taking the pictures, oil red $\mathrm{O}$ stained lipid droplets were extracted by $1 \mathrm{~mL}$ of absolute isopropyl alcohol and quantified by measuring the absorbance at $540 \mathrm{~nm}$.

\subsection{Conventional and Real-Time RT-PCR}

Total cellular RNA was isolated from cultured cells and some bovine tissues obtained from 3 Holstein cows by the guanidine-isothiocyanate method using RNAiso reagent (Takara Bio, Shiga, Japan). RNA $(2 \mu \mathrm{g})$ was treated at $70^{\circ} \mathrm{C}$ for $10 \mathrm{~min}$ and reverse transcribed using 100 units of Maloney murine leukemia virus reverse transcriptase (Invitrogen), $50 \mathrm{pmol}$ of poly (dT) primer and $20 \mathrm{nmol}$ of dNTPs in a total volume of $20 \mu \mathrm{L}$ at $37^{\circ} \mathrm{C}$ for $1 \mathrm{~h}$. After heating at $94^{\circ} \mathrm{C}$ for $5 \mathrm{~min}$, PCR amplification was performed with 2.5 units Taq polymerase (Ampliqon, Herlev, Denmark), $3 \mathrm{mM} \mathrm{MgCl} 2$ and 50 pmol of forward and reverse primers specific for respective genes in a total volume of $25 \mu \mathrm{l}$. The primers of PCR for bovine RBP4 forward 5'TACGCCATGGCCAAGAAGGA-3`and reverse 5`CTCTGCCGCACGATTTTCTG-3`, bovine aP2 primer 5'AGGTACCTGGAAACTTGTCT-3 'and reverse 5'GACAACGTATCCAGCAGAA-3' and bovine G3PDH forward 5'- CCACTGTCCACGCCATCAACT-3' and reverse 5'TCAGATCCACAACAGACACG-3`. Denaturation of PCR was at $94^{\circ} \mathrm{C}$, while extension at $72^{\circ} \mathrm{C}$ for $60 \mathrm{sec}$. The PCR products were analyzed by electrophoresis in $1.5 \%$ agarose gel with ethidium bromide.

To confirm the amplification of RBP4, aP2 and G3PDH mRNA, the PCR products were subcloned into pGEM-T Easy vector (Promega; Madison, WI, USA). The nucleotide sequence of each cDNA was confirmed and cDNA were used as standards for real-time PCR.

To quantify the levels of RBP4 mRNA expression, real-time PCR was performed with a fluorescence thermal cycler (Light Cycler System, Roche Diagnostics and Basel, Switzerland).

\subsection{Northern Blot}

Total RNA $(20 \mu \mathrm{g})$ was resolved on $1 \%$ agaroseformaldehyde gel, transferred onto a nylon membrane (Hybond-N+; Amersham Pharmacutical Biotec., Buckinghamshire, UK) and cross-linked under UV light for 2 min. Both prehybiridization and hybridization were performed at $65^{\circ} \mathrm{C}$ for $2 \mathrm{~h}$ and overnight, respectively, in a buffer containing 7\% SDS, $0.5 \mathrm{M}$ Church's phosphate buffer, pH 7.2, $1 \mathrm{mM}$ EDTA and $0.5 \mathrm{mg} \mathrm{mL}^{-1}$ salmon sperm DNA. After prehybiridization, the membrane was sequentially hybridized with cDNA probe encoding bovine RBP4 and bovine G3PDH as internal control for loading. The probe was labeled with $\left[\alpha_{-}{ }^{32} \mathrm{P}\right]$ DCT using the megaprime TM DNA labeling systems (Amersham) according to the instructions provided. After hybridization the membrane was stringently washed for 20 min twice with $2 \mathrm{X} \mathrm{SSC}$ and $0.1 \%$ SDS and once with $0.1 \%$ SSC and $0.1 \%$ SDS at $65^{\circ} \mathrm{C}$ before exposure into a phospho-imaging plate overnight. Detection and quantification of the hybridization signals were carried out using Phospho-image analyzer (BAS 2500, FUJIFILM Tokyo, Japan).

\subsection{Western Blot Analysis for RBP4 in Media}

$15 \mathrm{~mL}$ of medium were separated simultaneously by SDS-PAGE (13\%gel) under reducing conditions. Thereafter, the proteins were electroblotted onto a PVDF membrane (ImmobilonTM, Millipore and Bedford MA, USA). The membrane was blocked for $1 \mathrm{~h}$ at room temperature in $5 \%(\mathrm{w} / \mathrm{v})$ skimmed milk in a buffer [20 $\mathrm{mM}-\mathrm{Tris}-\mathrm{HCl}(\mathrm{pH} 7.5), 0.15 \mathrm{M}-\mathrm{NaCl}$ and $0.1 \%$ Tween $20]$ and then incubated with the anti-RBP4 sera (1:2000) overnight at $4^{\circ} \mathrm{C}$. The membrane was washed five times with the wash buffer and incubated with horseradish peroxidase-conjugated goat anti-rabbit IgG antibody (1: 4000, Zymed Labora-tories Inc., South San Francisco CA, USA) for $1 \mathrm{~h}$ at room temperature. Visualization was performed using an enhanced chemiluminescence detection system (Millipore) according to the manufacturer's instructions. The intensities of the immunoreactive bands were analyzed densitometrically using the NIH Image program

\subsection{Statistical Analysis}

Results were expressed as means \pm S.E.M. Statistical analysis was done by ANOVA and Fischer's post hoc test, with $\mathrm{p}<0.05$ being considered as statistically significant.

\section{RESULTS}

\subsection{Expression of RBP4 in Bovine Adipose Tissue}

In the present experiment we investigated RBP4 expression in different tissues taken from Holstein cows. RT-PCR revealed that RBP4 was expressed in bovine subcutaneous adipose tissue but its expression was lower than that in liver (Fig. 1). 


\subsection{Induction of Adipogenic Differentiation in Bovine Preadipocytes Reduced RBP4 Expression}

Next we examined RBP4 expression and the correlation between it and adipogenesis in bovine adipocytes. Stromal vascular cells prepared from Holstein subcutaneous adipose tissue and Japanese black steers subcutaneous and intramuscular adipose tissues were differentiated till day 12 . The adipogenic differentiation of these cells was conformed by lipid accumulation in the differentiated cells, which was detected by oil red $\mathrm{O}$ stain (Fig. 2A) and expression of adipogenic differentiation marker gene, adipocytes specific fatty acid binding protein (aP2). AP2 expression could not be detected in all cell types at day 0 . However, its expression could be detected from day 2 of differentiation and increased there after (Fig. 2B).

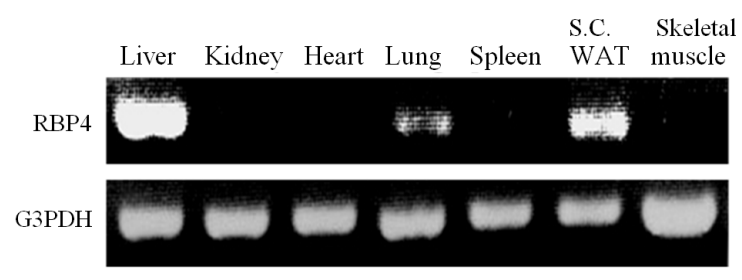

Fig. 1. RBP4 mRNA expression in bovine tissues
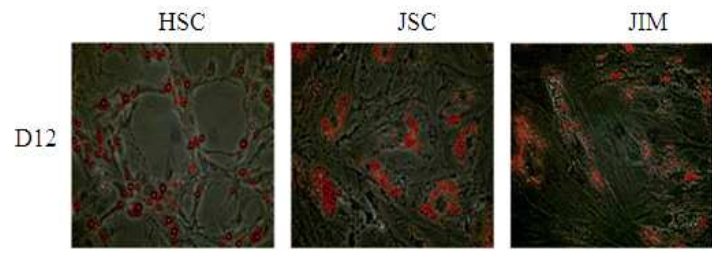

(a)
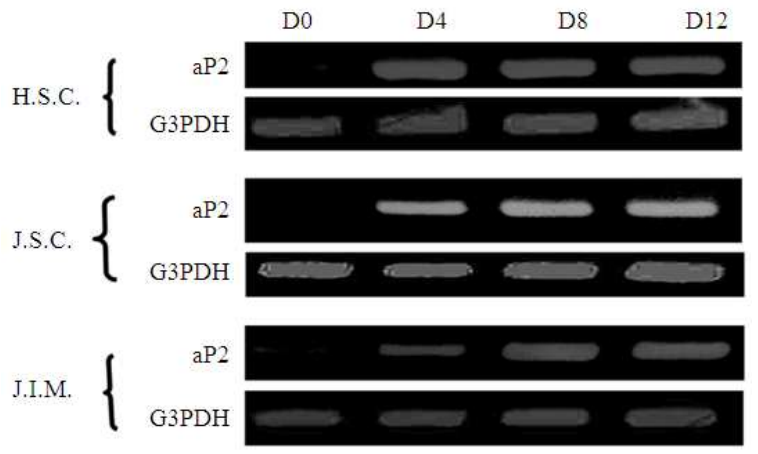

(b)

Fig. 2. Adipogenic differentiation of bovine adipocytes

Northern and Western blot analysises revealed that RBP4 was expressed and secreted from both pre- and mature adipocytes of all cell types (Fig. $3 A$ and $3 B$ ). RBP4 expression and secretion were highly abundant in preadipocytes. However, its expression and secretion were significantly reduced by induction of adipogenic differentiation in all cell types (Fig. 3A and 3B).
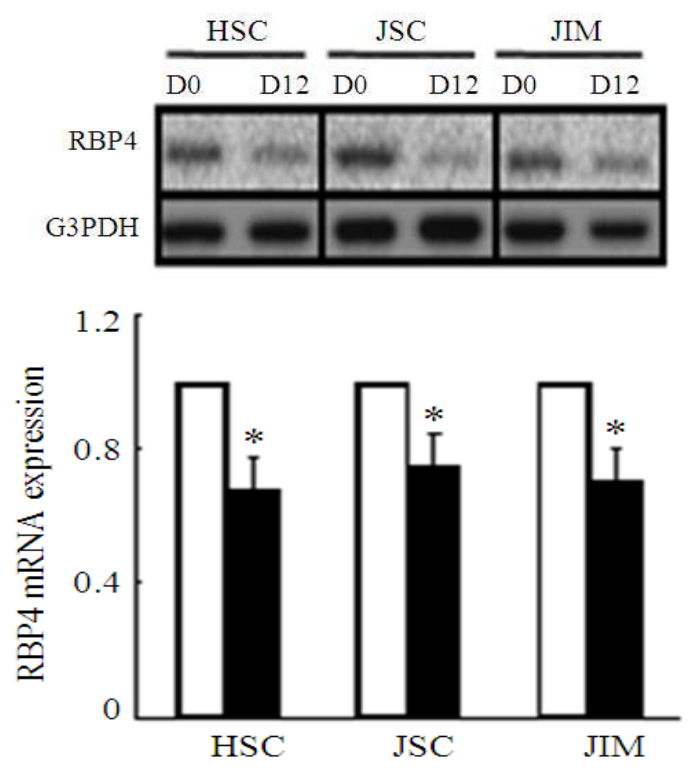

(a)
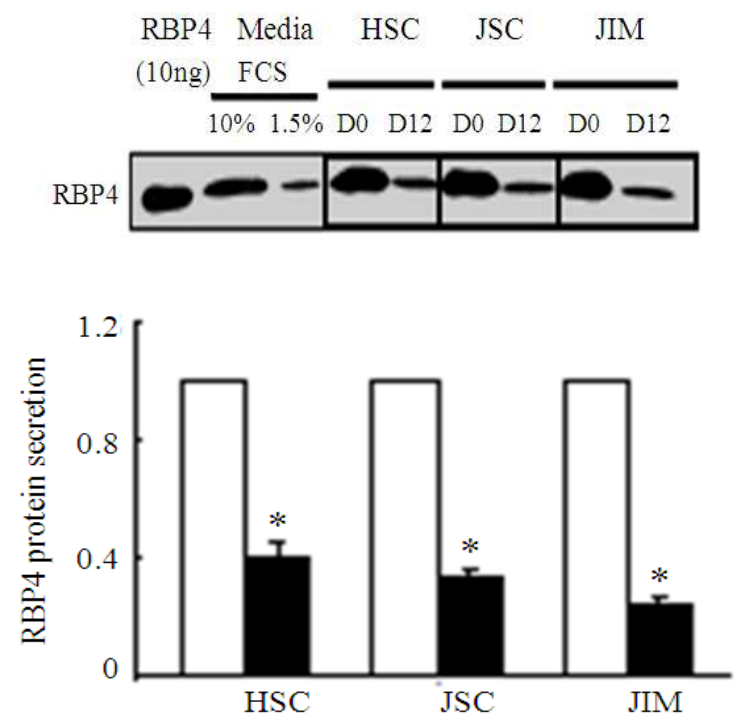

(b)

Fig. 3. Expression and secretion of RBP4 from bovine adipocytes 


\subsection{Regulation of RBP4 Expression by Retinoic Acid in Bovine Adipocytes}

Our previous study demonstrated that Japanese black steers' intramuscular adipocytes cultured in high glucose medium accumulated more lipids than those cultured in normal glucose medium. All-trans Retinoic Acid (RA) reduced lipid accumulation in cells cultured in normal glucose medium, while it enhanced lipid accumulation in cells cultured in high glucose medium (data under review).

Here we examined the regulation of RBP4 expression and secretion by retinoic acid in intramuscular adipocytes. Interestingly, RBP4 mRNA expression and its protein secretion were greatly reduced in Japanese black steer intramuscular adipocytes cultured in high glucose medium compared to those cultured in normal glucose medium (Fig. 4A, 4B). RBP4 expression and secretion from intramuscular adipocytes cultured in normal glucose medium was moderately reduced by addition of RA however, their levels still higher than those in control cells cultured in high glucose medium (Fig. 4A, 4B). In addition, RA almost diminished RBP4 expression and secretion from intramuscular adipocytes cultured in high glucose medium (Fig. 4A, 4B). Thus there was a negative correlation between adipogenesis and expression of RBP4 in bovine intramuscular adipocytes.

To verify whether the regulation of RBP4 expression and adipogenesis in subcutaneous adipocytes, is similar to that in intramuscular adipocytes. Stromal vascular cells prepared from Japanese black steers' subcutaneous adipose tissue were cultured and treated with RA like that prepared from intramuscular adipose tissue. RA significantly decreased RBP4 mRNA expression in Japanese black steers' subcutaneous adipocytes in the presence or absence of sodium acetate (substrate for fatty acid biosynthesis in subcutaneous adipocytes) (Fig. 5A). RA itself had no significant effect on lipid accumulation in subcutaneous adipocytes. Interestingly to note, RA enhanced the lipid accumulation in these cells after addition of acetate to the medium (Fig. 5B). Therefore, the effect of RA on adipogenesis and RBP4 expression is depot specific.

Finally, we investigated whether the regulation of RBP4 expression and adipogenesis is strain dependent. Here we assessed the effect of RA on RBP4 mRNA expression and lipid accumulation in adipocytes isolated from Holstein cows' subcutaneous adipose tissues. RA had no significant effect on RBP4 expression and lipid accumulation in these cells (Fig. 6A, B). So the effect of RA on RBP4 expression and adipogenesis is strain dependent.
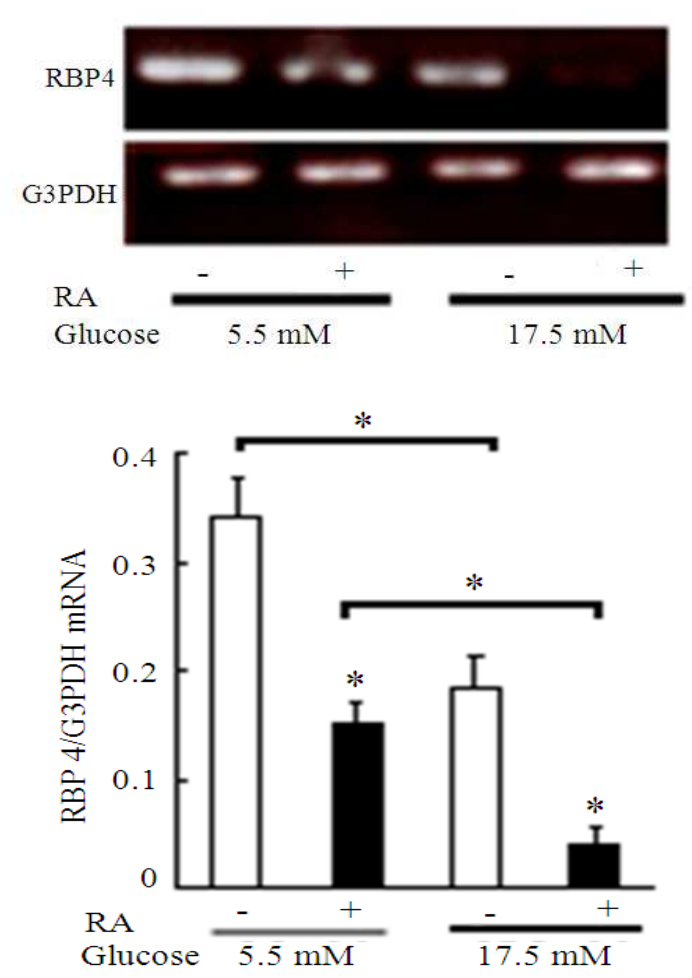

(a)
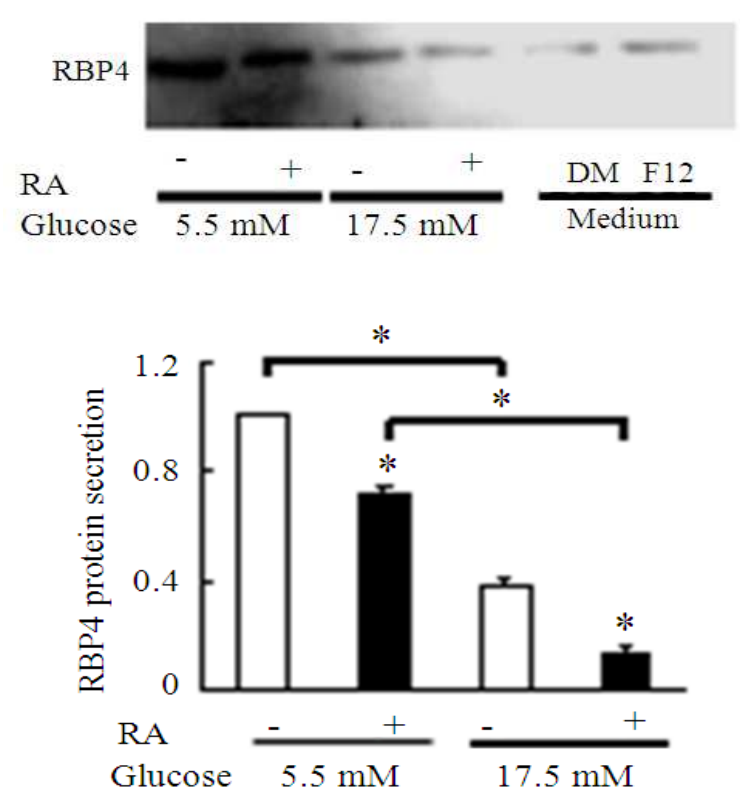

(b)

Fig. 4. Retinoic acid modified RBP4 expression in intramuscular adipocytes 


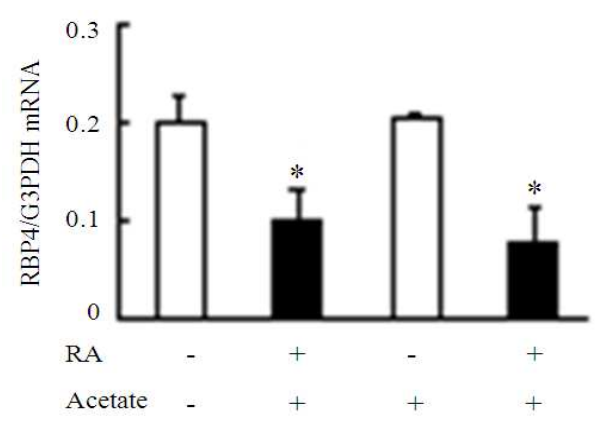

(a)

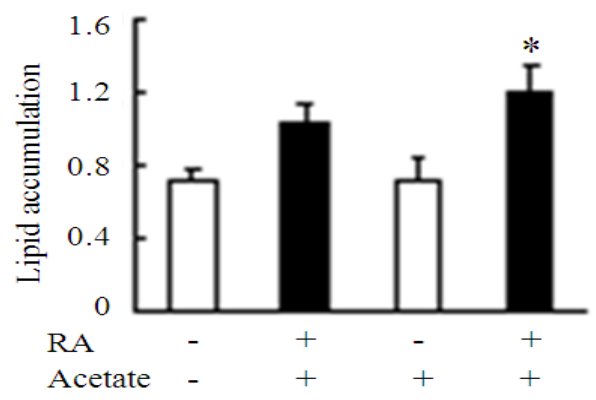

(b)

Fig. 5. Retinoic acid decreased RBP4 expression in subcutaneous adipocytes

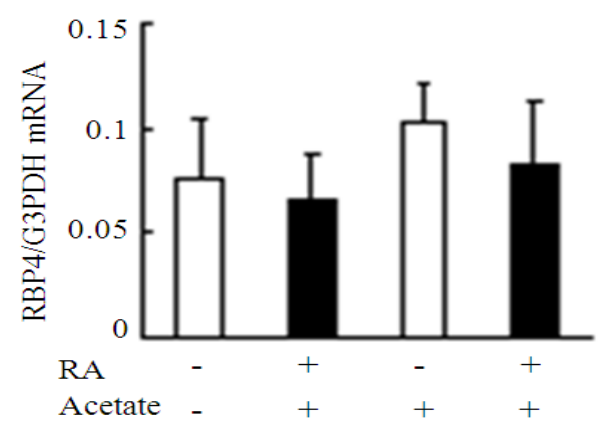

(a)

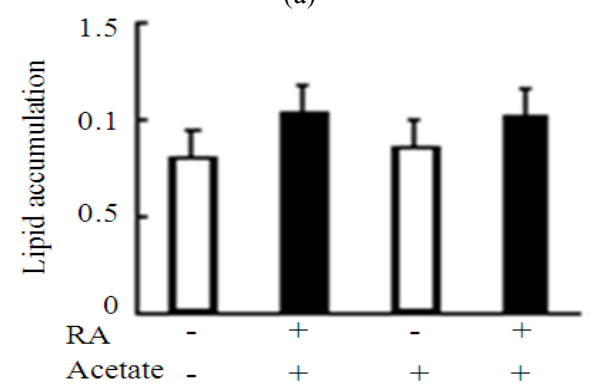

(b)

Fig. 6. Retinoic acid had no effect on RBP4 expression in Holstein subcutaneous adipocytes.

\section{DISCUSSION}

In this study, we provide novel evidence for a negative correlation between adipogenesis and RBP4 expression and secretion from bovine intramuscular adipocytes as well as a down-regulatory effect of RA and glucose on RBP4 expression and secretion.

Up to date there is no report concerning expression of RBP4 and its role in adipogenesis in bovine adipose tissues and adipocytes. However, some reports demonstrated the expression and secretion of RBP4 by adipose tissue and adipocytes in other species (Makover et al., 1989; Tsutsumi et al., 1992; Jessen and Satre, 2000). Our study revealed some differences in the pattern of RBP4 expression and secretion from bovine adipocytes. RBP4 expression and secretion from bovine preadipocytes were abundant and extremely reduced by induction of adipogenic differentiation of these cells into mature adipocytes. In contrast, RBP4 expression and secretion from rodent and human preadipocytes were negligible and increased by differentiating them into mature adipocytes (Tsutsumi et al., 1992; Zovich et al., 1992; Janke et al., 2006). These differences in RBP4 secretion from bovine adipocytes may have impact on the role of RBP4 in adipogenesis in bovine adipocytes. Because it was indicated that RBP4, especially that produced from adipose tissue, interferes with glucose uptake and insulin sensitivity in mice adipocytes (Yang et al., 2005) and attenuates insulin signaling in human adipocytes (Ost et al., 2007). Smith et al. (2009) and our previous study (data under review) reported that glucose is essential for adipogenesis in bovine intramuscular adipocytes. In the present study we found that glucose has a suppressive effect on RBP4 expression and secretion from intramuscular adipocytes. Moreover, our previous results (data under review) showed that RA enhanced the lipid accumulation in intramuscular adipocytes cultured in high glucose medium. However, the present results revealed that RA has a great suppressive effect on the RBP4 expression and secretion from these cells. Our finding was in line with Manolescu et al. (2010) who stated that RA administration in ob/0b mice decreased both serum RBP4 and retinol levels and increased both glucose consumption and the insulin sensitivity. Our finding and Manolescu finding can be explained by the suppressive effect of RA on the RBP4 production in mice adipose tissue, liver and primary adipocytes (Mercader et al., 2008). However, RBP4 expression has been reported to be unaffected either by retinol in differentiating BFC-1 $\beta$ cells (a preadipocytes cell line derived from mouse BAT) (Zovich et al., 1992) or by treatment of primary cultures of rat adipocytes with RA for $24 \mathrm{~h}$ (Okuno et al., 1995). Though, species 
differences cannot be discarded. In addition, exposure of subcutaneous adipocytes of Japanese black steers in the present study to RA alone has no effect on lipid accumulation; this was in an agreement with (GorocicaBuenfil et al., 2007). Interesting to note, by addition of acetate into the medium RA increased the lipid accumulation in these cells. Similar to its effect on the RBP4 expression in intramuscular adipocytes RA significantly reduced RBP4 expression in subcutaneous adipocytes. All these findings together provide an evidence for negative relationship between RBP4 expression and secretion from bovine adipocytes and the adipogenesis. This notion can be supported by the ideas stated that insulin resistance in mice is related to adipose-derived rather than liver-derived RBP4 because manipulation of adipose-derived RBP4 enhanced insulin sensitivity without affecting serum RBP4 level (Yang et al., 2005) Ost et al. (2007) added, all trans RA treatment down-regulated RBP4 expression in mice adipocytes not in liver while it enhanced glucose tolerance and insulin sensitivity of the animals. Although all of these evidence indicating a negative correlation between RBP4 expression and secretion from bovine adipocytes and adipogenesis, we found that RA decreased both adipogenesis and RBP4 expression and secretion in intramuscular adipocytes cultured in normal glucose medium. The suppressive effect of RA on adipogenesis may be due to the suppressive effect of RA on another adipogenic inducing factors like Sterol Regulatory Element Binding Protein-1 (SREBP-1) as was found in our previous study (data under review) that RA in normal glucose level suppressed SREBP-1 in bovine and mouse adipocytes, or to its suppressive action on the expression of PPAR $\gamma$ (Ribot et al., 2001; Brandebourg and $\mathrm{Hu}, 2005)$. These data may provide new insights on the mechanism of adipocytes differentiation in terms of the possibility of increasing marbling and meat quality grade without incurring health or performance problems associated with retinol restriction. Responsiveness of adipocytes differentiation to in vivo dietary modulations concerning retinol and energy formulations remains to be determined.

In contrast to its effect on the RBP4 expression and adipogenesis in Japanese black steer adipocytes, RA has no significant effect on the adipogenesis and RBP4 expression in Holstein subcutaneous adipocytes. That finding was consistence with that of (Hodat, 1995) who stated that beef marbling was not affected by the vitamin A status in Holstein steers and also with (GorocicaBuenfil et al., 2007). This can be explained by the fact that RBP4 regulation is independent from retinol in Holstein cows (Eldaim et al., 2010).

\section{CONCLUSION}

This study indicated that, induction of adipogenic differentiation and RA treatments have a suppressive effect on RBP4 expression in bovine adipocytes. That suggests a negative correlation between the adipogenesis and RBP4 expression in bovine adipocytes and possible inhibitory effect of RBP4 on adipogenesis.

\section{ACKNOWLEDGMENT}

We want to thank Professor Kzahiuro Kimura, Laboratory of Biochemistry, Department of Biomedical Sciences, Graduate School of Veterinary Medicine, Hokkaido University, Japan for his help as he supplied us with some materials used in this study.

\section{REFERENCES}

Eldaim, M.A.A., A. Kamikawa, M.M. Soliman, M.M. Ahmed and Y.O. Ogura et al., 2010. Retinol binding protein 4 in dairy cows: Its presence in colostrum and alteration in plasma during fasting, inflammation, and the peripartum period. J. Dairy Res., 77: 27-32. PMID: 19785912

Arnett, A.M., M.E. Dikeman, C.W. Spaeth, B.L. Johnson and B. Hildabr, 2007. Effects of vitamin A supplementation in young lambs on performance, serum lipid, and longissimus muscle lipid composition. J. Anim. Sci., 85: 3062-3071. PMID: 17785601

Blomhoff, R. and H.K. Blomhoff, 2006. Overview of retinoid metabolism and function. J. Neurobiol., 66: 606-630. PMID: 16688755

Brandebourg, T.D. and C.Y. Hu, 2005. Regulation of differentiating pig preadipocytes by retinoic acid. J. Anim. Sci., 83: 98-107. PMD: 15583048

Berry, D.C., S.M. O'Byrnec, A.C. Vreeland, W.S. Blanerc and N. Noy, 2012. Cross talk between signaling and vitamin A transport by the retinolbinding protein receptor STRA6. Mol. Cell. Biol., 32: 3164-3175.

Dixon, J.L. and D.S. Goodman, 1987. Studies on the metabolism of retinol-binding protein by primary hepatocytes from retinol-deficient rats. J. Cell Physiol., 130: 14-20. PMID: 3805126

Gorocica-Buenfil, M.A., F.L. Fluharty, T. Bohn, S.L. Schwartz and S.C. loerch, 2007. Effect of low vitamin A diets with high-moisture or dry corn on marbling and adipose tissue fatty acid composition of beef steers. J. Anim. Sci., 85: 3355-2255.3366. DOI: $10.2527 /$ jas.2007-0172 
Hodat, K., 1995. The relationship between vitamin A and meat quality in fattening cattle. Proc. Japanese Soc. Anim. Nutr. Metab., 39: 157- 171.

Janke, J., S. Engeli, M. Boschmann, F. Adams and J. Bohnke et al., 2006. Retinol-binding protein 4 in human obesity. Diabetes, 55: 2805-2810. PMID: 17003346

Jessen, K.A. and M.A. Satre, 2000. Mouse retinol binding protein gene: Cloning, expression and regulation by retinoic acid. Mol. Cell Biochem., 211: 85-94. PMID: 11055551

Kawada, T., N.A. Oki, Y. Kamei, K. Maeshige and S. Nishiu et al., 1990. Comparative investigation of vitamins and their analogues on terminal differentiation, from preadipocytes to adipocytes, of 3T3-L1 cells. Comparative Biochem. Physiol., 96: 323- 326. DOI: 10.1016/0300-9629(90)90699-S

Kawaguchi, R., J. Yu, J. Honda, J. Hu and J. Whitelegge et al., 2007. A membrane receptor for retinol binding protein mediates cellular uptake of vitamin A. Sci., 315: 820-825. PMID: 17255476

Makover, A., D.R. Soprano, M.L. Wyatt and D.S. Goodman, 1989. Localization of retinolbinding protein messenger RNA in the rat kidney and in perinephric fat tissue. J. Lipid Res., 30: 171180. PMID: 2469758

Manolescu., D.C., A. Sima and P.V. Bhat, 2010. All-trans retinoic acid lowers serum retinol-binding protein 4 concentrations and increases insulin sensitivity in diabetic mice. J. Nutr., 140: 311-316. PMID: 20032483

Marinari, L., C.M. Lenich and A.C. Ross, 1987. Production and secretion of retinol-binding protein by a human hepatoma cell line, HepG2. J. Lipid Res., 28: 941-948. PMID: 2822827

Mercader, J., N. Granados, M.L. Bonet and A. Palou, 2008. All-trans retinoic acid decreases murine adipose retinol binding protein 4 production. Cell Physiol. Biochem., 22: 363-372. DOI: 10.1159/000149815

Ohyama, M., K. Matsuda, S. Torii, T. Matsui and H. Yano et al., 1998. The interaction between vitamin A and thiazolidinedione on bovine adipocyte differentiation in primary culture. J. Anim. Sci., 76: 61-65. PMID: 9464885

Okuno, M., V.E. Caraveo, D.S. Goodman and W. Blaner, 1995. Regulation of adipocyte gene expression by retinoic acid and hormones: effects on the gene encoding cellular retinol-binding protein. J. Lipid Res., 36: 137-147. PMID: 7706939
Ost., A., A. Danielsson, M. Liden, U. Eriksson and F.H. Nystrom et al., 2007. Retinol-binding protein-4 attenuates insulin-induced phosphorylation of IRS1 and ERK1/2 in primary human adipocytes. Faseb J., 21: 3696-3704. DOI: 10.1096/fj.07-8173com

Redonnet, A., C. Ferrand, C. Bairras, P. Higueret and C. Noel-Suberville et al., 2008. Synergic effect of vitamin A and high-fat diet in adipose tissue development and nuclear receptor expression in young rats. Br. J. Nutr., 100: 722-730. DOI: $10.1017 / \mathrm{S} 0007114508967568$

Ribot, J., F. Felipe, M.L. Bonet and A. Palou, 2001. Changes of adiposity in response to vitamin A status correlate with changes of PPAR gamma 2 expression. Obes. Res., 9: 500-509. PMID: 11500531

Safonova, I., C. Darimont, E.Z. Armi, P. Grimaldi and G. Ailhaud et al., 1994. Retinoids are positive effectors of adipose cell differentiation. Mol. Cell Endocrinol., 104: 201-211. PMID: 7988747

Shulman, A.I. and D.J. Mangelsdorf, 2005. Retinoid X receptor heterodimers in the metabolic syndrome. New Eng. J. Med., 353: 604-615. DOI: 10.1056/NEJMra043590

Smith, S.B., H. kawachi, C.B. Choi, C.W. Choi and $\mathrm{G}$. Wu et al., 2009. Cellular regulation of bovine intramuscular adipose tissue development and composition. J. Anim. Sci., 87: E72-E82. PMID: 18997081

Tsutsumi, C.M., L. Okuno, R. Tannous, M. Piantedosi and D.S. Allan et al., 1992. Retinoids and retinoidbinding protein expression in rat adipocytes. J. Biol. Chem., 267: 1805-1810. PMID: 1370481

Yang, Q., T.E. Graham, N. Mody, F. Preitner and O.D. Peroni et al., 2005. Serum retinol binding protein 4 contributes to insulin resistance in obesity and type 2 diabetes. Nature, 436: 356-362. PMID: 16034410

Zovich, D.C., A. Orologa, M. Okuno. L.W. Kong and D.A. Talmage et al., 1992. Differentiationdependent expression of retinoid-binding proteins in BFC-1 beta adipocytes. J. Biol. Chem., 267: 1388413889. PMID: 1629187 